\title{
EFEKTIVITAS MISSOURI MATHEMATICS PROJECT BERBANTUAN DOMAT DITINJAU DARI HASIL BELAJAR MATEMATIKA SMK TUNAS MUDA BERKARYA BATAM TAHUN AJARAN 2017/2018
}

\author{
MATHEMATICAL PROJECTS DOMATIC MISSOURI EFFECTIVENESS REVIE WED \\ FROM RESULTS LEARNING MATHEMATICS BATAM YOUNG VOCATIONAL \\ SCHOOL OF VOCATIONAL SCHOOL YEAR 2017/2018 ACADEMIC YEAR
}

\author{
Jelita Bahagia Kinanti Pardosi ${ }^{1}$, Nailul Himmi ${ }^{2}$ \\ Program Studi Pendidikan Matematika, Fakultas Keguruan dan Ilmu Pendidikan \\ Universitas Riau Kepulauan, Kepulauan Riau, Indonesia. \\ jelitabahagiakinanti@gmail.com
}

\begin{abstract}
Abstrak
Penelitian ini bertujuan untuk mengetahui keefektifan model MMP berbantuan Domat, keefektifan model konvensional serta perbedaan efektivitas model MMP berbantuan Domat dengan model konvensional ditinjau dari hasil belajar matematika di SMK Tunas Muda Berkarya kelas X. Jenis penelitian yaitu eksperimen semu, dengan Posttest-Only Control Group Design. Populasinya seluruh siswa kelas X SMK Tunas Muda Berkarya. Teknik pengambilan sampel yaitu purposive sampling, yaitu X AK (21 siswa)kelas eksperimen dan X AP (21 siswa) kelas kontrol. Dengan menggunakan instrumen soal uraian sebanyak 10 soal, dimana semua butir valid dan nilai reliabilitas 0,77614. Hasil penelitian menunjukkan bahwa penerapan model MMP berbantuan Domat efektif ditinjau dari hasil belajar matematika SMK Tunas Muda Berkarya kelas X dengan $t_{\text {hitung }}(6,36)>t_{\text {tabel }}$ (1,725). Penerapan model konvensional tidak efektif ditinjau dari hasil belajar matematika SMK Tunas Muda Berkarya kelas $X$ dengan $t_{\text {hitung }}(1,537)<t_{\text {tabel }}(1,725)$. Terdapat perbedaan efektivitas model pembelajaran MMP berbantuan Domat dan model konvensional ditinjau dari hasil belajar matematika SMK Tunas Muda Berkarya kelas $X$ dengan $t_{\text {hitung }}(8,962)>t_{\text {tabel }}(2,021)$. Jadi dapat disimpulkan bahwa model MMP berbantuan Domat efektif ditinjau dari hasil belajar matematika SMK Tunas Muda Berkarya Batam untuk kelas X. Salah satu saran untuk guru yaitu guru dapat menggunakan model MMP berbantuan Domat sebagai salah satu alternatif model pembelajaran untuk meningkatkan hasil belajar matematka.
\end{abstract}

Kata Kunci: Missouri Mathematics Project, Domat, Hasil Belajar Matematika

\begin{abstract}
This study aims to determine the effectiveness of MMP assisted Domat, the effectiveness of conventional models, and differences in effectiveness of MMP assisted Domat and conventional model viewed from mathematics learning result at SMK Tunas Muda Berkarya class X. This research type is quasi experiment with Posttest-Only Control Group Design. The population of this study is all students of class X SMK Tunas Muda Berkarya Batam 2017/2018. The sampling technique used by the purposive sampling. And experiment class is X AK (21 students) and control class is X AP (21 students). With use the instrument essay 10 numbers, in this case all of it valid. The reliability is 0,77614. The results showed the application of MMP assisted Domat is effective in terms of mathematics learning result in SMK Tunas Muda Berkarya class $X$ with $t_{\text {count }}(6,36)>t_{\text {table }}(1,725)$. The application of conventional model is not effective in terms of mathematics learning result in SMK Tunas Muda Berkarya Batam for class $X$ with $t_{\text {count }}(1,537)<t_{\text {tabel }}(1,725)$. There is difference of effectiveness of MMP assisted learning Domat and conventional model from mathematics learning result at SMK Tunas Muda Berkarya Batam for class $X$ with $t_{\text {count }}(8,962)>t_{\text {tabel }}(2,021)$. So, the conclute is The application of MMP assisted Domat is effective in terms of mathematics learning result in SMK Tunas Muda Berkarya class X. There is one advice for the teacher that is teacher can use MMP assisted Domat as the alternative model for incrase the results of mathematics.
\end{abstract}

Keywords: Missouri Mathematics Project, Domat, Mathematics Learning Outcomes 


\section{PENDAHULUAN}

Matematika berperan penting dalam perkembangan Ilmu Pengetahuan dan Teknologi (IPTEK). Matematika juga merupakan mata pelajaran yang masuk ujian nasional, baik pada jenjang pendidikan dasar, menengah, maupun atas. Hal tersebut menunjukkan pentingnya matematika dalam memenuhi penyediaan potensi sumber daya manusia yang handal, yaitu manusia yang memiliki pemikiran kritis, sistematis, logis, kreatif, dan kemampuan bekerja sama. Kompetisi tersebut diperlukan agar siswa dapat memiliki kemampuan memperoleh, mengelola dan memanfaatkan informasi untuk bertahan hidup pada keadaan yang selalu berubah, tidak pasti dan kompetitif. Namun hingga kini kemampuan tersebut belum berkembang secara optimal. Hal ini terlihat dari hasil belajar siswa yang masih rendah.

Permasalahan lain yang terlihat adalah rendahnya hasil belajar matematika siswa SMK Tunas Muda Berkarya Batam. Hal ini terlihat dari hasil observasi peneliti yaitu masih banyaknya siswa kelas X yang nilai matematikanya masih dibawah Kriteria Ketuntasan Minimal (KKM) yang ditentukan sekolah yaitu 70 pada Ujian Tengah Semester. Dari 72 jumlah siswa hanya 24 siswa yang mencapai KKM dengan persentase ketuntasan 34,3\%, dan 48 siswa yang tidak tuntas dengan persentase 65,7\%. Salah satu penyebab rendahnya hasil belajar matematika siswa adalah bahwa siswa kurang aktif dalam bertanya maupun memberikan pendapat mereka. Ketika guru bertanya apakah siswa paham dengan materi, semua menjawab paham. Namun ketika guru memanggil siswa ke depan untuk mengerjakan soal, banyak siswa yang mengeluh tidak paham. Selain itu dari hasil wawancara terbuka dengan siswa didapat informasi bahwa rata-rata siswa mengeluh matematika merupakan pelajaran yang sulit karena kebanyakan soal-soal latihan maupun ujian berbeda dengan contoh soal yang diberikan guru. Sebagian siswa juga kesulitan untuk memahami materi yang disampaikan oleh guru. Ketika guru menjelaskan materi sebagian siswa ada yang paham dan ada yang tidak paham. Serta siswa kurang berpartisipasi selama proses pembelajaran. Kegiatan pembelajaran masih didominan oleh guru, yaitu guru menjelaskan materi di depan kelas dan siswa hanya mendengarkan dan mencatat apa yang disampaikan oleh guru. Ini membuat suasana belajar di kelas sangat monoton, dan kurang menarik, serta siswa cendrung kurang paham tentang materi yang disampaikan guru.

Berkaitan dengan hal tersebut, perlu adanya perubahan dalam menelaah proses belajar siswa. Siswa harus mampu mengembangkan ide dan juga memahami materi matematika yang diajarkan oleh guru. Siswa juga harus dibiasakan untuk berlatih 
mengerjakan soal atau permasalahan baik itu secara individual ataupun perkelompok. Guna untuk menyiapkan siswa menjadi manusia yang handal yang memiliki pemikiran kritis, sistematis, logis, kreatif, dan kooperatif.

Dalam penelitian ini dipilih model Missouri Mathematics Project (MMP). Dimana menurut Setiawan (2008: 37) “MMP adalah salah satu model pembelajaran terstruktur dengan pengembangan ide serta perluasan konsep matematika dengan disertai adanya latihan soal baik itu perkelompok atau individu”. Maksudnya adalah guru tidak dominan menjelaskan materi di depan kelas namun siswa akan diberikan kesempatan mengembangkan ide mereka untuk menyelesaikan permasalahan-permasalah yang diberikan guru guna memperoleh kesimpulan dari materi yang diajarkan. Model MMP ini dirancang untuk menggabungkan kemandirian dan kerja sama antar kelompok. Model pembelajaran MMP terdiri dari 5 langkah yaitu antara lain: (1) review (2) pengembangan (3) latihan terkontrol (4) seatwork (5) penugasan atau PR. Missouri Mathematics Project (MMP) memiliki banyak kelebihan di antaranya banyak materi yang dapat disampaikan kepada siswa, dan siswa dapat terampil mengerjakan soal, karena banyaknya latihan yang diberikan. Penelitian yang relevan dengan penelitian ini adalah penelitian Arifin (2010). Dalam penelitiannya telah disimpulkan secara keseluruhan bahwa melalui model pembelajaran MMP dapat meningkatkan hasil belajar siswa.

Selain penggunaan model pembelajaran yang efektif, media pembelajaran juga merupakan komponen dalam keberhasilan belajar mengajar. Penggunaan media pembelajaran juga dapat menunjang aktivitas siswa di kelas. Banyak macam media pembelajaran yang dapat digunakan sebagai alat bantu dalam melaksanakan model MMP. Salah satunya adalah dengan menggunakan media pembelajaran Domino Matematika (Domat). Kartu domino disini bukanlah kartu domino yang biasa digunakan pada umumnya, melainkan suatu media untuk pembelajaran. Tujuan penggunaan Domat ini adalah agar siswa banyak berlatih mandiri, meningkatkan pemahaman dan penguasaan terhadap materi serta terampil menjawab banyak soal yang terkait. Selain itu, bentuk dari Domat yang menarik membuat siswa merasa senang bermain meskipun secara tidak langsung sudah mempelajari matematika. Adapun bentuk yang dibuat seperti kartu domino yang di dalamnya berisi soal-soal matematika yang berkaitan dengan materi matematika yang harus diselesaikan oleh siswa. Penelitian yang relevan dengan penelitian ini adalah penelitian Suprapto (2011). Berdasarkan hasil penelitian 
ini, disimpulkan bahwa penggunaan kartu domino dapat meningkatkan hasil belajar siswa kelas XI Madrasah Aliyah Batamiyah Tahun Pelajaran 2010/2011.

Namun pendapat ini masih perlu untuk diuji, maka dari itu berdasarkan uraian di atas, penelitian ini bertujuan untuk mengetahui pengaruh model pembelajaran MMP berbantuan Domat ditinjau dari hasil belajar matematika SMK Tunas Muda Berkarya Batam.

\section{METODOLOGI}

Jenis penelitian ini adalah eksperimen semu dengan desain Posttest-Only Control Group Design. Penelitian ini dilaksanakan pada siswa kelas X SMK Tunas Muda Berkarya Batam, dengan populasi berjumlah 72 siswa. Pengambilan sampel dalam penelitian ini menggunakan Purposive Sampling. Sampel penelitian berjumlah 42 siswa, yang terdiri atas 21 siswa kelas eksperimen dan 21 siswa kelas kontrol. Pada kelas eksperimen diberi perlakuan model MMP berbantuan Domat, sedangkan kelas kontrol model konvensional.

Instrumen penelitian yang digunakan adalah soal uraian. Sebelum digunakan untuk mengambil data terlebih dahulu dilakukan analisis instrumen yang meliputi validitas, dan reliabilitas. Uji validitas tes menggunakan validitas isi, dimana validitas isi melibatkan 3 orang validator, kemudian dilanjutkan dengan uji Aiken's. Dan uji reliabilitas menggunakan rumus Cronbach Alpha. Berdasarkan hasil validitas semua data valid dan reliabel (0,77614).

Teknik analisis data yang digunakan untuk menguji hipotesis penelitian ini adalah uji satu pihak (one sample t-test) serta Polled Variance. Dimana sebelum itu dilakukan uji normalitas menggunakan uji Kolmogorov-Smirnov dan uji homogenitas menggunakan uji-F. Uji normalitas dan homogenitas diuji dengan berbantuan aplikasi SPSS for windows version 22.0. Sedangkan hipotesis menggunakan aplikasi MS.Excel, dimana jika Sig. $\geq \alpha(0,05)$ maka Ho diterima sedangkan $H_{0}$ ditolak jika $t_{\text {hitung }}>t_{\text {tabel }}$.

\section{PEMBAHASAN}

Adapun hasil deskripsi dari pemberian tes (5 soal uraian) kepada siswa kelas eksperimen dan kontrol adalah sebagai berikut: 
Tabel 1. Deskripsi Hasil Penelitian Kelas Eksperimen

\section{Statistics}

Nilai

\begin{tabular}{|lr|r|}
\hline N & Valid & 21 \\
Mean & Missing & 0 \\
Median & & 83,57 \\
Mode & 85,00 \\
Std. Deviation & 85 \\
Variance & 9,765 \\
Minimum & 95,357 \\
Maximum & 60 \\
Sum & 100 \\
\hline
\end{tabular}

Tabel 2. Deskripsi Hasil Penelitian Kelas Kontrol

Statistics

Nilai

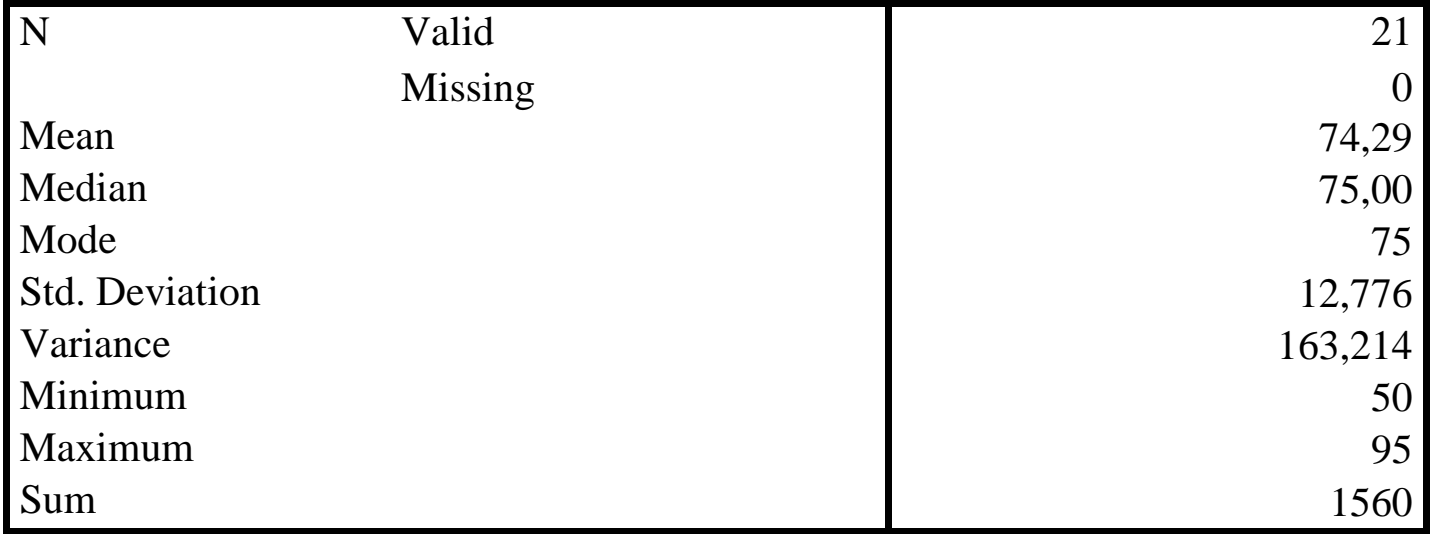

Selanjutnya dilakukan uji normalitas data yang disajikan pada Tabel 3:

Tabel 3. Hasil Uji Normalitas

Tests of Normality

\begin{tabular}{|ll|r|r|rr|}
\hline \multirow{2}{*}{ Model } & \multicolumn{3}{|c|}{ Kolmogorov-Smirnov $^{\mathrm{a}}$} \\
\cline { 2 - 6 } & Statistic & \multicolumn{1}{c|}{ df } & \multicolumn{2}{c|}{ Sig. } \\
\hline Nilai & Model MMP \& &, 177 & 21 & &, 084 \\
& $\begin{array}{l}\text { Domat } \\
\text { Model }\end{array}$ & & &, $200^{*}$ \\
\hline
\end{tabular}

*. This is a lower bound of the true significance.

a. Lilliefors Significance Correction 
Berdasarkan Tabel 15, normalitas nilai hasil belajar kelas eksperimen sebesar Sig. $(0,084)$ dan kelas kontrol sebesar Sig. $(0,200)$, keduanya sama-sama lebih dari $\alpha(5 \%)$. Dengan demikian, dapat disimpulkan bahwa data berdistribusi normal. Berikutnya dilakukan uji homogenitas yang disajikan pada Tabel 4:

Tabel 4. Hasil Uji Homogenitas

Test of Homogeneity of Variances

\begin{tabular}{|c|c|c|c|}
\hline Levene Statistic & df1 & df2 & Sig. \\
\hline 1,309 & 1 & 40 & ,259 \\
\hline
\end{tabular}

Berdasarkan Tabel 16, diperoleh nilai Sig. $(0,259)>\alpha(0,05)$. Sehingga dapat disimpulkan bahwa data penelitian di atas variansinya homogen. Untuk uji hipotesis 1 dilakukan uji t satu pihak. Berdasarkan uji t satu pihak di dapat $t_{\text {hitung }}=6,36$ dan $t_{\text {tabel }}=1,725$ sehingga 6,36 >1,725 maka $\mathrm{H}_{0}$ ditolak. Dapat disimpulkan model pembelajaran MMP berbantuan Domat efektif ditinjau dari hasil belajar matematika di SMK Tunas Muda Berkarya Batam untuk kelas X. Untuk uji hipotesis 2 dilakukan juga uji t satu pihak. Berdasarkan uji t satu pihak di dapat $t_{\text {hitung }}=1,537$ dan $t_{\text {tabel }}=1,725$ sehingga $1,537<1,725$ maka $H_{0}$ diterima. Dapat disimpulkan model konvensional tidak efektif ditinjau dari hasil belajar matematika di SMK Tunas Muda Berkarya Batam untuk kelas X. Sedangkan hipotesis 3 diberikan uji Polled Variance. Berdasarkan uji di dapat $t_{\text {hitung }}(8,962)$ dan $t_{\text {tabel }}$ (2,021). sehingga 8,962 > 2,021 maka $\mathrm{H}_{0}$ ditolak. Dapat disimpulkan terdapat perbedaan efektivitas model pembelajaran MMP berbantuan Domat dan model konvensional ditinjau dari hasil belajar matematika di SMK Tunas Muda Berkarya Batam untuk kelas X.

Dari uji hipotesis pertama, dapat dilihat bahwa model pembelajaran MMP berbantuan Domat efektif ditinjau dari hasil belajar matematika di SMK Tunas Muda Berkarya Batam untuk kelas X. Hal ini dikarenakan model pembelajaran MMP yang berisikan langkahlangkah urutan untuk menemukan konsep, memudahkan siswa memahami materi, serta model pembelajaran yang didesain untuk membantu guru dalam hal efektivitas penggunaan latihan-latihan agar mencapai hasil yang luar biasa. Sejalan dengan pendapat Qonik dalam Sholihah (2015) menyatakan latihan-latihan yang dimaksud adalah lembar tugas proyek dengan tujuan untuk membantu siswa agar lebih mudah memahami materi yang dijelaskan oleh guru. 
Uji hipotesis kedua membuktikan bahwa model konvensional tidak efektif ditinjau dari hasil belajar matematika di SMK Tunas Muda Berkarya Batam untuk kelas X. Hal ini dikarenakan kegiatan pembelajaran masih didominan oleh peneliti, yaitu peneliti menjelaskan materi di depan kelas dan siswa hanya mendengarkan dan mencatat apa yang disampaikan oleh peneliti. Ini membuat suasana belajar di kelas sangat monoton, dan kurang menarik. Menurut Susanto (2013: 192) mengemukakan bahwa penerapan model pembelajaran konvensional, yakni ceramah, tanya jawab, dan pemberian tugas atau pekerjaan rumah (PR). Sistem pengajaran ini menyebabkan siswa tidak berpartisipasi aktif dalam mengikuti pembelajaran, dan siswa kurang aktif dalam bertanya maupun memberikan pendapat mereka, sehingga dikhawatirkan siswa tidak dapat meningkatkan aktivitas belajar matematika untuk meningkatkan hasil belajarnya.

Pada uji hipotesis ketiga, dapat disimpulkan bahwa terdapat perbedaan efektivitas model pembelajaran MMP berbantuan Domat dan model konvensional ditinjau dari hasil belajar matematika di SMK Tunas Muda Berkarya Batam untuk kelas X. Menggunakan model MMP berbantuan Domat ini lebih praktis, karena berisi ringkasan materi. Selain itu juga ada LKS, kartu Domat, dan lembar kerja mandiri siswa sehingga mempermudah siswa dalam memahami materi melalui LKS, terampil mengerjakan soal-soal latihan melalui kartu Domat, dan cukup melibatkan siswa dalam proses pembelajaran, serta melatih siswa belajar kooperatif dan kemandirian siswa. Sedangkan model konvensional dimana siswa tidak berpartisipasi aktif dalam mengikuti pembelajaran, dan siswa kurang aktif dalam bertanya maupun memberikan pendapat mereka, sehingga dikhawatirkan siswa tidak dapat meningkatkan aktivitas belajar matematika untuk meningkatkan hasil belajarnya. Menurut Good \& Grouws dalam Setiawan (2008) memperoleh temuan bahwa guru yang merencanakan dan mengimplementasikan lima langkah pembelajaran matematikanya, akan lebih sukses dibanding dengan mereka yang menggunakan pendekatan tradisional, dalam hal ini termasuk juga model konvensional.

\section{KESIMPULAN DAN SARAN}

Adapun kesimpulan dalam penelitian ini:

1. Penerapan model pembelajaran MMP berbantuan Domat efektif ditinjau dari hasil belajar matematika di SMK Tunas Muda Berkarya Batam untuk kelas X.

2. Penerapan model konvensional tidak efektif ditinjau dari hasil belajar matematika di SMK Tunas Muda Berkarya Batam untuk kelas X. 
3. Terdapat perbedaan efektivitas model pembelajaran MMP berbantuan Domat dan model konvensional ditinjau dari hasil belajar matematika di SMK Tunas Muda Berkarya Batam untuk kelas X.

Dan saran pada penelitian ini adalah pembelajaran dengan model MMP berbantuan Domat dapat digunakan sebagai model pembelajaran matematika di sekolah, karena telah terbukti meningkatkan hasil belajar siswa baik secara individual maupun klasikal.

\section{REFERENSI}

Arifin, M. Z. (2010). Penerapan Model Pembelajaran Missouri Mathematics Project (MMP) untuk Meningkatkan Hasil Belajar Matematika Materi Pokok Fungsi pada Peserta Didik Kelas VIII MTs YASI Kronggen Brati Tahun Pelajaran 2010/ 2011. Skripsi. Semarang: Program Strata 1 Jurusan Tadris Matematika Fakultas Tarbiyah IAIN Walisongo Semarang.

Setiawan. (2008). Strategi Pembelajaran Matematika SMA. Yogyakarta: Depdiknas.

Sholihah, Fitrotus. (2015). Keefektifan Pembelajaran Matematika dengan Model Missouri Mathematics Project terhadap Pemahaman Konseptual dan Prosedural Siswa KelasX. Skripsi, Jurusan Matematika Fakultas Matematika dan Ilmu Pengetahuan Alam Universitas Negeri Semarang.

Suprapto, Heri. (2011). Upaya Meningkatkan Hasil Belajar Siswa dengan Pendekatan Permainan Kartu Domino pada Pokok Bahasan Rumus Trigonometri Jumlah Dua Sudut dan Selisih Dua Sudut Siswa Kelas IX Madrasah Aliyah Batamiyah Tahun Pelajaran 2010/2011. Skripsi, Perpustakaan UNRIKA.

Susanto, Ahmad. (2013). Teori Belajar dan Pembelajaran di Sekolah Dasar. Jakarta: Kencana Prenada Media Group. 